IJBPAS, December, 2021, 10(12): 4521-4535

ISSN: $2277-4998$

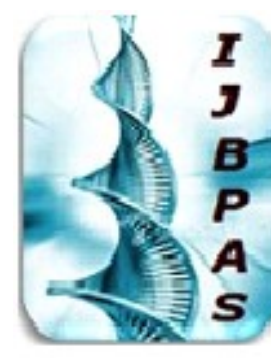

International Journal of Biology, Pharmacy

and Allied Seiences (IJBPAS)

'A Bridge Between Caboratory and Q Qnder'

www.ibpas.com

\title{
IGBO TRADITIONAL MEDICINE AND CHINESE MEDICAL PRACTISING: A COMPARATIVE ANALYSIS
}

\section{OKORO KINGSLEY N}

Department of Philosophy/ Religion and Cultural Studies Alex Ekwueme Federal University Ndufu-Alike Ebonyi State, Nigeria

*Corresponding Author: Okoro Kingsley N: E Mail: okechukwup.cugwu@gmail.com Received 19 ${ }^{\text {th }}$ Jan. 2021; Revised 20 ${ }^{\text {th }}$ Feb. 2021; Accepted $14^{\text {th }}$ March 2021; Available online $1^{\text {st }}$ Dec. 2021

\section{https://doi.org/10.31032/IJBPAS/2021/10.12.5769}

\section{ABSTRACT}

Traditional Igbo Medicine (TIM) and Traditional Chinese medicine (CM) remain part of the most ancient yet living traditions. In Igbo land, traditional healers prescribing medicinal plants are the most easily accessible and affordable health resource available to the local community and at times the only therapy that subsists. Nonetheless, there is still a paucity of updated comprehensive compilation of promising medicinal plants from the African continent, compared to its counterpart, the Chinese Medicine. China has been successful in promoting its therapies with more research and science-based approach, while the Igbo traditional medicine still needs more extensive scientific research and evidence base. This paper gives an overview of basic principles and commonalities of traditional Igbo medicine and Chinese Medicine, and discusses key determinants of success, which these great traditions need to address to compete in global markets.

Keywords: Traditional Igbo Medicine, Chinese medical Practice, Chinese Medicine, Comparative, Analysis, Complementary and alternative medicine, Traditional medicine

\section{INTRODUCTION}

Traditional medicine (TM), popularly known as complementary and alternative medicine, folk medicine, ethno-medicine or native healing, is the oldest type of health system that has stood the test of time. It is an primordial and culture-bound technique of 
therapeutic that humans have used to handle and treat various diseases that have endangered their existence and survival [1]. Therefore, TM is wide and diverse and several societies have evolved different types of natural healing methods that are captured under the broad idea of TM, e.g. Hence, TM is broad and diverse. Consequently, different societies have evolved different forms of indigenous healing methods that are captured under the broad concept of TM, e.g. Chinese, Indian and African traditional medicines, part of which is the Igbo traditional medicine [1]. Indian and African traditional medicines, part of which is the Igbo traditional medicine [1]. This explains the basis why there is no single generally conventional description of the term. In spite of, one of the most satisfactory definitions of TM has been provided by the World Health Organisation (WHO). According to the World Health Organisation, $\mathrm{TM}$ is "the summation of the knowledge, skills and practices based on the theories, philosophy and experiences to different cultures, whether understandable or not, used in the protection of health, as well as in the prevention, analysis, enhancement or treatment of physical and mental illnesses" [1, 2]. According to [3], increased side effects, lack of healing treatment for quite a lot of chronic diseases, high cost of novel drugs, microbial resistance and up-andcoming diseases are some reasons for improved public curiosity in complementary and alternative medicines. Thus, it was postulated that by 2010 , at least two-thirds of the United States inhabitants will be utilising one or more of the alternative therapeutic approaches. Use of native drugs of natural origin forms a key part of such therapies; more than 1500 herbals are sold as nutritional supplements or ethnic traditional medicines (Legal status of traditional medicine, complementary/alternative medicine, 2001).

Pharmaceutical industries have changed their methods in support of natural product drug growth and discovery [4]. Hence, in Europe, AnalytiCon Discovery has stressed on drug discovery based on natural product chemistry (Available at http://www.ac-discovery.com.). In the Asia-Pacific area, MerLion Pharmaceuticals in Singapore has many structures and abilities needed for natural product based drug discovery (Available at http://www.merlionpharma.com/index.html). China has effectively promoted its own therapies over the sphere with a sciencebased approach. Growing fame of traditional Chinese Medicine (TCM) can be evidenced by the quick increase in amount of approved Chinese medicine providers in the United States. The Chinese government has agreed 
to create several export-oriented TCM giants in the coming years [5]. Constant efforts in support of indigenous therapies by China have put TCM in a laudable position.

The methods of health care structure developed by the native peoples rose from the contact with their unique environment and conviction. Despite the disdain suffered by this healing system from western halftruths who see it as being crude, unscientific and archaic, etc, it has continued to exist and thrive and has always met the health needs of the people [6]. The victory of traditional health practices, efficient diagnosis and cure of some ailments that defiled conventional and well-known cure by African and oriental cultures in particular China, have led to a second thought in the utilization of traditional therapeutic methods in health care. One of these traditional healing methods and practices is that of the Igbo in Nigeria. The Igbo traditional health care system has enjoyed support from natives who believe in it and consider it as a more inexpensive and efficient option to western medication [7]. Among the Igbo, sickness is normally referred to as 'aru mgbu' (body pain), 'oria' (sickness) etc. Apart from recognizing illness as a major problem, they link the causes to a number of agents such as sorcery, breaking of taboos, spiritual disease and witchcraft [8]. In Nigeria, people have deep conviction and reliance on the services of the traditional practitioners for their health care needs. Approximately 75 percent of the population still prefer to solve their health issues by consulting the traditional healers $[\mathbf{8}$, 9]. The World Health Organisation (W.H.O.) has also acknowledged the vital role that traditional medicine plays in the 21 st century, particularly in the areas of prevention and managing of illnesses such as malaria, tuberculosis, HIV/AIDS, and others. Western scientific community perceive traditional medicines guardedly and stress the concerns related to its quality, development and research, [10-15]. This paper is therefore a comparative analysis of the Igbo traditional medicine and the Chinese medical practices. It aims to highlight the probable similarities between these two great traditions while defining the challenges that traditional Chinese medicine and the Igbo traditional medicine need to tackle to become acceptable to the world community.

\section{Global Markets and Acceptance}

The worldwide pharmaceutical market was worth US $\$ 550$ billion in 2004 [16]. The herbal business shares about US \$62 billion with good expansion potential. The World Bank reports that trade in therapeutic plants, botanical drug products and raw materials are 
growing at a yearly growth rate between 5 and $15 \%$ [17]. In 2001, US $\$ 17.8$ billion was spent in the United States on nutritional supplements, US $\$ 4.2$ billion of it for botanical remedies [18]. China's yearly herbal drug manufacturing is valued at US $\$ 48$ billion with sales abroad of US \$3.6 billion [19] while Japan, Singapore, Korea and Hong Kong are the chief importer of traditional Chinese Medicine attracting 66\% share of China's botanical drugs export [20]. Similarly, traditional medicine is still in use in present day Africa after thousands of years of its subsistence without much reported incidents of unpleasant effects [21, 22, 23]. In countries like Mali, Ghana, Zambia and Nigeria, the first line of cure for $60 \%$ of children with high fever ensuing from malaria is the use of herbal remedy $[\mathbf{2 4}, \mathbf{2 5}]$, revealed an increasing demand for traditional Medicine in the case of rheumatic and neurological complaints in Burkina Faso. In Ghana, around $70 \%$ of the population rely principally on Traditional Medicine [26]. Around 27 million South Africans (usually the black South Africans) use Traditional Medicine to cure an array of ailments [2730], discovered that traditional health care has contributed extensively to the cure of degedege (convulsions) in Tanzania. In some cases, patients use Traditional Medicine concurrently with contemporary medicine in order to assuage sufferings connected with disease and illness. [4, 5], stated that a considerable number of hypertensive patients receiving orthodox treatment at the tertiary health facility in Lagos, Nigeria, also used traditional remedy. Equally, the rising demand for traditional Medicine in Europe, Asia and America has also been recognized. It has been made known that between $40 \%$ and $60 \%$ of the populace in Western Pacific Region use traditional medicine to treat diverse ailments [8]. There are suggestions that unconventional medicine is acquiring widespread acceptance in Australia, France and Canada with $46 \%, 49 \%$ and $70 \%$ of the inhabitants respectively using traditional medicine [9]. In the United Kingdom (UK), approximately $40 \%$ of the physicians make some alternative referrals [10]. The WHO's regional office for Americas' [11], report indicates that $71 \%$ and $40 \%$ of populations in Chile and Colombia have used TM [12]. Consequently, WHO has recognized the contributions of traditional healers to general health delivery mostly in developing countries [13-15]. According to the World Health Organisation the indigenous healers have contributed to a wide range of health care needs that include disease prevention, management and cure of non-communicable 
diseases as well as psychological and gerontological health problems [20]. There are also mounting evidences that traditional medicine is effectual in the management of chronic illnesses [23].

\section{Basic Principles of Igbo Traditional Medicine and Chinese Medical Practising}

The Igbo traditional medicine and Chinese medical practices have many similarities. The focal point of both systems is on the patient rather than ailment. Both systems basically intend to promote health and improve the quality of life, with healing strategies for treatment of particular diseases or symptoms in holistic fashion. About half of the botanical sources used as medicines have similarities; moreover, both systems have similar philosophies directed towards enabling classification of individuals, diseases and materials. Traditional Chinese Medicine regards the human at the center of the universe as a receiver between celestial and earthly elements [7]. Water, metal, wood, fire and earth are the five elements of the material world. The world is a distinct unit and its movement gives rise to yin and yang, the two main antithetic aspects. The real meaning of the term yin and yang is 'opposites', such as the positive and the negative. However, Chinese suppose that yin and yang is not complete but relative. In line with the modern view of homeostasis, yin and yang are interchanged to meet the perception that 'yang declines and yin rises' or 'yang is raised to produce a decline of yin'. The four bodily humours (qi, blood, moisture and essence) and internal organ systems (zang fu) play a key part in balancing the yin and yang in a person's body. Appropriate formation, maintenance and circulation of these energies are crucial for health. When the two energies fall out of harmony, disease develops. The physician takes recognises this notion while treating patients. Drugs or herbs are used to correct this disparity of yin-yang in the human body [8].

In Igbo view, every sickness comprises the unseen, spiritual or supernatural origin and noticeable or natural origins. Hence they commonly perceived ailments especially the protracted ones like insanity as dual rooted. As Iroegbu puts it, "For the Igbo, health is something shared inter-corporeally and intersubjectively, both in the worldly and otherworldly or the visible and invisible realms [13]. Accordingly, the traditional physician called Dibia develops proficiency along wide-ranging or particular lines. African (Igbo) traditional medicine in its various forms is holistic connecting both the body and the mind. The traditional healer 
characteristically diagnoses and treats the mental basis of an ailment before prescribing medicines, particularly medicinal plants to treat the symptoms [15]. In most parts of Africa, medicinal plants are by far, the most accessible health resource available to the community. Also, they are most often the favoured option for the patients. For most of these people, traditional healers offer counselling, information and treatment to patients and their families in a personal way as well as having an understanding of their patient's environment [16].

\section{Quality of the Botanical Drugs}

Consistency in composition and biological activity are critical requirements for the safe and efficient use of therapeutic agents. Quality is the vital determinant of safety and effectiveness of botanical drugs; nevertheless, botanical preparations hardly ever meet the standards of quality, which refers to measures and markers for examining and ascertainimg the strength of botanical raw materials or extracts or formulations thereof [12]. Chromatographic methods and chemical marker assisted categorization of the botanicals does not ensure constant biological activity or stability [13]. Therefore, production of quality botanical medicines has become a challenge to regulatory systems, scientific organizations and firms.

unpublished work on "Traditional Healthcare in Nsukka: An Ethno-archaeological Approach" identified the kinds of ailments connected to Nsukka people among which are: malaria (Iba), boils, snake bite, swollen legs (Odema), swelling stomach (Afo ototo), infertility, swollen breast (Ezhi-era), Apollo (Eye - disease), stomach ache (Afo oruru), dysentery, 'Mkpoyi' (Bronchi pneumonia), convulsion (Osise) and tonsillitis (Mgbapia). The causes of the ailments range from spasmodic contractions of muscles, mosquitoes bite, abnormal growth in the throat, germs, bad blood, to sociocultural/religious factors like magical powers, evil spirits, poisons, sacrifices etc. Okonkwo stated that it is bothersome that the writer does not know the pharmacological agent(s) used in the preparation of the treatment of these ailments. Conversely, further disclosure in her research report is that plants, which serve as normal diet, are used in preparing the remedy. It is therefore, not only the crude properties of the plant that are valuable in the treatment process; but also the magical or spiritual forces implanted by nature in all living things and the contributions of ancestral spirits and God. Ugwu also added out that Igbo traditional 
doctors (dibias) are believed to be able to protect people's lives from accidents, witches and other supernatural powers or influences. However, the belief in these protective powers still exists, but its effectiveness remains doubtful. The healing and protecting measures recognized among Nsukka indigenes by [12] are: incision made on parts of the body by the traditional physician and medicine prepared in lotion or powdered form; medicinal belts (amulets) or rings worn around the waist and finger(s); bitter kola (Garcinai kola) (Igogoro) a seed containing fluid for detoxification and believed to be an antidote against suspected poison by sorcerers; 'Uro' (Earth chalk), believed to posses curative powers when mixed with many chemicals, medicinal plants and animals wastes.

In her study on "Traditional Healthcare Practices in Nnewi North Local Government Area of Anambra State" [1] classified traditional healthcare practices in Nnewi North into five: herbalists, diviners, bone setters, traditional psychiatrists, and traditional birth attendants. She noted that traditional healthcare practitioners take over this practice from their forefathers and that patients consult daily. For the herbalist, the spirit of 'Agwu' assist him either by day - by leading him into the bush and unveiling medicinal herbs to the person; or by night in one's dream. [2], noted that once in a while, sacrifices are offered to the gods or through 'dibia-aja' in order to pacify them. She describes bone setters as those traditional practitioners who specialize in mending broken bones (broken legs and hands), severe pains in the spinal cord, waist etc. They make use of local ointments, herbs, roots, sand, alligator pepper, animal product etc. for treatment of fractures. The traditional psychiatrist (dibia ara) on the hand, specializes in healing mental illness caused by evil spirits or invoked by people on their enemies. Though, the author failed to identify the various types of leaves/roots/herbs used in traditional medicines and the diseases which they treat, thus, living a gap in the body of knowledge on traditional healthcare practices in Igbo land. In a similar vein, a former DirectorGeneral of the National Agency for Food and Drug Administration and Control (NAFDAC) articulated the challenges being faced in regulating traditional medicines [4]. These include, lack of documentation, insufficient coordination of the practitioners' activities, poor communication between the practitioners and their patients, secrecy of actual contents and/or difficulty in determining actual ingredients. Additionally, 
most of the claims of the traditional practitioners are said to be unconfirmed and their post-market monitoring has been difficult. On the contrary, China has successfully overcome such difficulties by modernizing its traditional medicine profession with government-sponsored Good Agricultural Policies (GAPs) and Good Manufacturing Practices (GMPs). GAPs emphasize selection of the right germplasm with high content of established active ingredients. The cultivation practices offer Standard Operating Procedures for use of fertilizers, irrigation systems and disease management associated with insects and pest prevention and cure. GAPs also institute standards for deleterious and harmful contaminants like heavy metals, pesticide residues and microbes in plants. All producers of traditional Chinese medicine are mandated to conform to guidelines laid down by China's State Drug Administration (SDA) by 2004 and farms producing raw ingredients must adhere to SDA-imposed standards by 2007. Accordingly, 1470 companies have qualified for GMPs while 570 failed to meet the standards (China's new quality control, functional foods and nutraceuticals, 2003). For marketing of herbal medicine in China, special requirements such as quality dossier, safety and effectiveness evaluation and precise labelling criteria are necessary. New herbal drugs must be approved according to the Drug Administration Laws. Similar integrated efforts are needed to raise the image of the Igbo traditional medicines in the global business (Table 1).

\section{Research in Traditional Igbo Medicine and Chinese Medicine}

Natural products extracts of curative importance are of vital significance as pools of structural and chemical mixture. A reevaluation on countrywide pharmacopoeias from numerous nations indicated at least 120 different chemical components from diverse plants that have benefit as lifesaving medicines [8]. This was attained through chemical and pharmacological vetting of only $6 \%$ of the total plant types. Unused, concealed richness in plants need to be brought to light and studied in order to provide cure for diseases like cancer, diabetes, AIDS, etc. Botanical immuno-drugs from native medicine can offer newer prospects to bio-prospect varied and synergistic chemical moieties, which in blending might be active on numerous targets and perk up the curative range [12].

PUBMED, Google scholar and Science direct are the widely recognized web databases of scientific literature. However, comparative citations for Igbo traditional 
medicine and Chinese medicine using different key words plus the patent data shows that the visibility of Igbo traditional medicine remains much lower as compared with TCM (see table below). Chinese medicine became successful in crossing philosophical hurdles through steady reworking of the basic system (Table 2).

Table 1: Some Igbo Medicinal Plants with their medicinal values

\begin{tabular}{|c|c|c|c|c|}
\hline Scientific name & Common name & Local name & Plant part used & Ailment treated \\
\hline Dacryodes eludes & Native pear & Ube & Leaves & $\begin{array}{c}\text { Skin disease, hypertension, } \\
\text { cough }\end{array}$ \\
\hline Carica papaya & Pawpaw & Okwurubeke & Leaves, sap, fruit, root & $\begin{array}{l}\text { Malaria, typhoid, diabetes, } \\
\text { waist pain, convulsion, } \\
\text { syphilis, diarrhoea, dysentery, } \\
\text { potency in men }\end{array}$ \\
\hline $\begin{array}{c}\text { Terminalia } \\
\text { catappa }\end{array}$ & Terminalia & - & Leaves, stem, root & $\begin{array}{c}\text { Eye infection, skin diseases, } \\
\text { diarrhoea, dysentery }\end{array}$ \\
\hline $\begin{array}{c}\text { Citrullus } \\
\text { colocynthis }\end{array}$ & Melon & Egusi & Fruits, leaves, seed shell & $\begin{array}{c}\text { Skin disease, syphilis, laxative, } \\
\text { stomach ache }\end{array}$ \\
\hline $\begin{array}{c}\text { Telfairia } \\
\text { occidentalis }\end{array}$ & $\begin{array}{c}\text { Fluted } \\
\text { pumpkin }\end{array}$ & Ukwu & Leaves, flowers & Headache, anaemia, burns \\
\hline Cucurbita pepo & Pumpkin & Ugbogulu & Fruit pulp, seeds & $\begin{array}{c}\text { Prostrate disease, benign } \\
\text { tumour, urinary infection, } \\
\text { cystitis } \\
\end{array}$ \\
\hline Citrillus lantana & - & - & Seeds & $\begin{array}{c}\text { Snake bites, scorpion sting, } \\
\text { vermifuge }\end{array}$ \\
\hline Glycine max & Soy bean & Soya beans & Seeds, leaves, bark & $\begin{array}{c}\text { Eye infection, anaemia, } \\
\text { measles }\end{array}$ \\
\hline $\begin{array}{c}\text { Irvingia } \\
\text { gabonensis }\end{array}$ & Bush mango & Ugili & Leaves, whole plant & $\begin{array}{c}\text { Stomach ache, worm, skin } \\
\text { disease, infertility }\end{array}$ \\
\hline $\begin{array}{c}\text { Ocimum } \\
\text { gratssimum }\end{array}$ & Basil plant & Nchanu & Leaves, stem & $\begin{array}{l}\text { Haemorrhoid, typhoid, } \\
\text { stomach ache, cough, cold } \\
\text { catarrh, fever, baby cord, } \\
\text { chest pain, diarrhoea, anti- } \\
\text { bacterial, anti-fungal }\end{array}$ \\
\hline Salvia officinalis & Golden chia & Uzi & Leaves & $\begin{array}{c}\text { Diabetes, cough, ear infection, } \\
\text { stomach ache }\end{array}$ \\
\hline Thyme vulgari & Thyme & - & & $\begin{array}{c}\text { Laxative } \\
\end{array}$ \\
\hline
\end{tabular}

Adapted from Essien, et al., (2019)

Table 2: Citations and patent data for Traditional Igbo Medicine and Chinese Medicine (as on 20 ${ }^{\text {th }}$ June, 2020)

\begin{tabular}{|c|c|c|c|c|}
\hline Database & Keywords: TIM & Citations/Patent & $\begin{array}{c}\text { Keywords } \\
\text { TCM }\end{array}$ & Citations/patent \\
\hline PubMed & $\begin{array}{c}\text { Traditional Igbo Medicine } \\
\text { Igbo Medicine }\end{array}$ & 14 & $\begin{array}{c}\text { Traditional Chinese } \\
\text { Medicine } \\
\text { Chinese Medicine }\end{array}$ & $\mathbf{7 7 , 4 5 0}$ \\
\hline $\begin{array}{c}\text { Science } \\
\text { Direct }\end{array}$ & $\begin{array}{c}\text { Traditional Igbo Medicine } \\
\text { Igbo Medicine }\end{array}$ & 77 & $\begin{array}{c}\text { Traditional Chinese } \\
\text { Medicine } \\
\text { Chinese Medicine }\end{array}$ & $\mathbf{1 2 2 , 9 9 9}$ \\
\hline $\begin{array}{c}\text { Google } \\
\text { Scholar }\end{array}$ & $\begin{array}{c}\text { Traditional Igbo Medicine } \\
\text { Igbo Medicine }\end{array}$ & $\mathbf{3 7 5}$ & $\begin{array}{c}\text { Traditional Chinese } \\
\text { Medicine } \\
\text { Chinese Medicine }\end{array}$ & $\mathbf{3 9 6 , 1 1 1}$ \\
\hline
\end{tabular}


The foremost compound derived from Chinese herbal remedies to penetrate the western market was ephedrine, an amphetamine like stimulant from ma huang (Ephedra sinica). After that, was artimisinin, a powerful antimalarial from qinghao (Artemisia annua). In 2003, Chinese researchers commenced the second stage trial to examine the efficiency of a drug named kanglaite from iijen (Coix lachryma-jobi) for curing non-small-cell lung cancer [15]. This was the first medicine from the Chinese to go into clinical trials in the United States. Other drug molecules from traditional Chinese medicine are xue baoPG2 (general tonic from Astragalus membracaceus) and camptothecin analogs as CPT11 and topotecan (anticancer from Camptotheca accuminata), and they have a massive market. In 2002, a total of 1,141 diverse natural plant medicines were catalogued for their curative activities including a number of new single compounds from plants as arteannuin (antimalarial), indirubin (anticancer), etc. It must be stated that part of the twelve focal points in the Five-Year Plan of China's Ministry of Science and Technology was to modify research in traditional Chinese medicine. Pharmacopoeia of the People's Republic of China (2000) contains 992 monographs of Chinese basic medicines and traditional
Chinese patent medicines in which 76 new entrants and 248 monographs have been revised. Controlled clinical trials have been kicked off at several hospitals and research centres to confirm the efficiency and safety of the Chinese medicine [16, 19, 20, 25].

In contrast, in most developing countries, Nigeria for one, the knowledge on the use of plant resources for healing is fast declining due to non-unavailability of information and very little records of these important natural assets. Though a number of research workers have documented some medicinal plants from the Southeastern Nigeria, the information remain very little [26]. In a study by [22] on "Homestead horticultural crops: Alternative sources to alternative medicines/therapies in Ebonyi State, Southeastern Nigeria" a total of 44 horticultural plants species spread across 32 genera and belonging to 30 families were met. According to the study, the most important and commonly used horticultural plants with medicinal value is observed in the families of Palmae, Liliaceae, Cucurbitaceae, Piperaceae, Rutaceae, Zingiberaceae, Lamiaceae, Anacardiaceae, and Sapotaceae. The topmost plant species employed to cure ailments belong to the family Cucurbitaceae, indicating that it is the most vital family in the traditional medicine of the state in 
particular and Igbo land in general. The other essential families in respect to number of taxa with therapeutic uses in the state were Sapotaceae, Palmaceae, Anacardiaceae, Piperaceae, Lamiaceae, Liliaceae, Rutaceae, and Zingiberaceae. These families feature prominently in the traditional medicines of other parts of Igbo land and are reported in the flora and pharmacopoeia of Nigeria [15, 17, 19]. These families are usually given consideration during ethno botanical approaches to drug discovery because of their rich content of secondary metabolites such as alkaloids, tarpenes and steroids [20, 21, 23, 25]. Cucurbitaceae is of particular importance to the area. Five species were named for therapeutic use by the informants. The plant species of the family were pointed out in the curing of virtually all the illnesses of the most important categories recorded either singly or combined. [7], states that the scientific literature on traditional medicine has witnessed a rising number of literature geared towards assessing the efficiency of medical plants from Africa which are believed to have an essential contribution in the preservation of health and in the introduction of new treatments. Even so, there is still a shortage of updated comprehensive assemblage of capable medicinal plants from the African continent, and in particular, Igbo land. Thus, to reach a stage where traditional Igbo medicine is assured of becoming integrated into mainline medical treatment in not just Nigeria but worldwide, several obstacles must be overcome.

First, the ethnocentric and medicocentric inclinations of the Western hegemonic mindset that are usually displayed by most stakeholders in contemporary medicine remains a very serious challenge. It is a general belief in medical circle that traditional medicines resist scientific measures in terms of codification, neutrality, measurement, and classification. Even then, there are suggestions that the physical aspects of native medicine (i.e. the physical ingredients) can be scientifically studied and analysed. Consequently, the biggest problem is how to scientifically study the spiritual aspect of traditional Igbo medicine. Again, if incorporated, who provides training to medical doctors on the epistemology, ontology, and the efficacies of Igbo traditional medicine given the ethnocentric predisposition in modern medicine? That is, who determines the value and effectiveness of traditional medicine given the inherent epistemological and ideological characteristic discrepancies of both medicines? It is part of these difficulties that some scholars suggest 
that both native medicine and refined medicine be allowed to operate, develop and flourish independent of one another $[4,6,8$, 9]. "After all, the western people did not develop their medical aspect in order to integrate it with anyone else. Theirs was to first make themselves and later the rest of the world live a healthy life" [10]. From this perspective, if native medicine is drafted into modern medicine, it would further validate and promote the "supremacy" or "superiority" of the orthodox medicine thereby jeopardising the identity and integrity of traditional medicine in Africa.

\section{CONCLUSION}

Rapid social changes are taking place all over the world, especially in this era of globalization. These changes are in many areas including traditional medical ideas and institutions which are undergoing modification and expansions in order to meet the changing expectations and perceptions of the people. Thus, traditional Igbo medicine and Chinese medicine carry many generations' observations that have wellorganized and documented data, however, China has successfully promoted its own therapies and drugs like ginseng, ma huang and gingko with scientific evidences acceptable for the international community while that of Igbo and Nigeria in general, is still fighting to gain the needed attention. Therefore, there is the need for the Igbo people to pay serious attention to global trends in traditional medicine discourses for the benefit of all.

\section{RECOMMENDATIONS}

This study recommends as follows:

i. The approach of integrative medicine by selective inclusion of elements of traditional medicine alongside the modern methods of diagnosis has achieved great success in China. Therefore, promoters of traditional medicine in Nigeria must work towards wider integration of Igbo traditional medicine with modern methods. Nonetheless, Nigeria needs a clear policy for such integration without compromise on the strategies that are science-based.

ii. Efforts must be geared towards the establishment and validation of pharmacoepidemiological evidence regarding the safety and practice of Igbo traditional medicine.

iii.Pharmaco-economic studies on Chinese medicine and Igbo traditional are rare; hence, research in this area is paramount as it can help in understanding the costeffectiveness and cost-benefit of traditional medicine. Such research would help Nigeria especially at various levels 
including policies, quality standards, integration practices, research models and the complementary integration with public health as the central focus. Both traditional Igbo medicine and Chinese medical practices are great traditions with strong philosophical basis and could play an important role in new therapies, drug discovery and development processes.

\section{REFERENCES}

[1] Adefolaju, T., (2011). The Dynamics and Changing Structure of Traditional Healing System in Nigeria. International Journal of Health Research, 4(2): 99-106

[2] Adesina, K. (2008) Traditional Medicine in Nigeria. http://www.onlinenigeria.com/healt

[3] Amzat, J. and Abdullahi, A. A. (2008). 'Role of Traditional Healers in the Fight against HIV/AIDS'. EthnoMed, 2(2): 153-159

[4] Arazeem, A. A., (2011). Trends and challenges of traditional medicine in Africa. African Journal of Traditional Complementary and Alternative Medicine. 8(S):115-123 115

[5] Bhushan P., Dnyaneshwar, W., Pushpangadan, P., and Narendra, B., (2005). Ayurveda and Traditional
Chinese Medicine: A Comparative Overview. Published by Oxford University Press

[6] Cao Y, Shi Y, Zheng Y, Shi M, Lo SK. Blood-nourishing and hard softening capsule costs less in the management of osteoarthritic knee pain: a randomized controlled trial. Evid Based Complement Alternat Med; 2:363-8

[7] Carpentier, L. Prazuck, T. VincentBallereau, F. Ouedraogo, L. T. and Lafaix, C. (1995). Choice of Traditional of Modern Treatment in West Burkina Faso. World Health Forum. 16: 198-210.

[8] Report of the Ministry of Commerce of the People's Republic of China, (2003). A dream of globalizing the TCM market.

[9] Cardellina, J. H., (2002). Challenges and opportunities confronting the botanical dietary supplement industry. J Nat Prod; 65: 1073-84.

[10] Cheng J. T., (2000). Review: drug therapy in Chinese traditional medicine. J Clin Pharmacol; 40:445-50.

[11] China's new quality control, functional foods and nutraceuticals, 
(2003).

http://www.ffnuag.com/ASP/377/.

[12] Chukwuemeka, N. K., (2009). Traditional psychiatric healing in Igbo land, Southeastern Nigeria. African Journal of History and Culture (AJHC) Vol. 1 (2), pp. 036043.

[13] De Smet PA. Herbal remedies. New Engl J Med 2002; 347: 2046-56

[14] Essien, B. A., Essien, J. B. and Okocha, I. O., (2019). Homestead horticultural crops: Alternative sources to alternative medicines/therapies in Ebonyi State, Southeastern Nigeria. GSC Biological and Pharmaceutical Sciences, 09(02), 072-083

[15] Fabricant, D. S, and Farnsworth, N. R., (2001). The value of plants used in traditional medicine for drug discovery. Environ Health Perspect; $109: 69-75$

[16] Goswami A, Barooch, P. K., Sandhu, J. S., (2002). Prospect of herbal drugs in the age of globalization-Indian scinario. J Sci Ind Res; 61: 423-43.

[17] Gurib-Fakim, A. and Mahomoodally, M. F., (2013). "Afric \an flora as potential sources of medicinal plants: towards the chemotherapy of major parasitic and other infectious diseases- a review," Jordan Journal of Biological Sciences, vol. 6, pp. 77-84.

[18] Gibert, T. F., (1998). Reflections on traditional Chinese medicine and its pharmacopoeia. Ann Pharm Fr; 56: 282-5. 23.

[19] Humber J. M., (2002). The role of complementary and alternative medicine: accommodating pluralism. J Am Med Assoc; 288: 1655-6

[20] World Health Organization, (2001). Legal status of traditional medicine, complementary/alternative medicine: a worldwide review Geneva.

[21] Maggon, K., (2005). Best selling human medicine 2002-2004. Drug Discov Today; 11: 739-42

[22] Mahomoodally, M. F., (2013). Traditional Medicines in Africa: An Appraisal of Ten Potent African Medicinal Plants. Hindawi Publishing Corporation EvidenceBased Complementary and Alternative Medicine.

[23] Marccus, D. M., Grollman, A. P., (2002). Botanical medicines - the need for new regulations. New Engl J Med; 347: 2073-6 
[24] Normile, D., (2003). The new face of traditional Chinese medicine. Science; 299: 188-90.

[25] Okonkwo, E. (2012). Traditional Healing Systems Amon Nsukka Igbo.

http://www.researchgate.net/publica tion/273951184

[26] Okwor, C. E. O (1997) "Igbo Traditional Concept of Diseases and Therapeutic". Okikpe. Vol. 3. No.1. Enugu: SNAAP

[27] Patwardhan, B., Chopra, A., and Vaidya, A., (2003). Herbal remedies and the bias against Ayurveda. Curr Sci; 84: 1165-6. 10.

[28] Patwardhan, B., Gautam, M., (2005). Botanical immunodrugs: scope and opportunities. Drug Discov Today; 7: 495-502

[29] Seidl, P. R., (2002). Pharmaceuticals from natural products: current trends. An Acad Bras Cienc; 74: $145-50$

[30] Tang, J. L., Zhan, S. Y., and Ernst, E., (1999). Review of randomized controlled trials of traditional Chinese medicine. Br Med J.; 319: $160-1.50$. 